\title{
ANALISIS DAN ESTIMASI BIAYA BUBUR ORGANIK DAN PUDING RASA MITRA PROCIL KARAWANG
}

\author{
Annisa Indah Pratiwi \\ Program Studi Teknik Industri, Universitas Buana Perjuangan Karawang \\ Jl. HS Ronggowaluyo Telukjambe Timur, Karawang 41361 \\ email: annisa.indah@ubpkarawang.ac.id
}

\begin{abstract}
ABSTRAK
Analisis dan estimasi biaya diperlukan untuk mengetahui besar biaya produksi, harga pokok produksi, Break Even Point dan mengetahui profit suatu produk. Hal ini juga berlaku di outlet Mitra Sehat Indonesia (Procil) Karawang yang banyak mendapatkan order dari pelanggan, sehingga peneliti tertarik untuk menganalisis perusahaan Mitra Procil Karawang tersebut dengan menggunakan metode service hours dalam menghitung penggunaan asset secara penuh, full costing method dalam menentukan Harga Pokok Produksi (HPP), gross margin pricing (Mark Up) method dalam menentukan harga jual dan Break Even Point dalam menentukan minimal batas penjualan untuk mendapatkan keuntungan. Dari hasil penelitian selama periode satu bulan diperoleh Harga Pokok Produksi sebesar Rp. 7.791.594, Harga Pokok Penjualan sebesar Rp. 9.739.492, harga jual per unit bubur organik sebesar Rp. 3.500, harga jual per unit puding sebesar Rp. 2.500, BEP unit bubur organik sebesar 861,8 porsi, BEP Rupiah bubur organik sebesar Rp. 3.016.300, BEP unit puding sebesar 214 cups, BEP Rupiah pudding sebesar Rp. 536.729 dan total profit sebesar Rp. 15.079.000.
\end{abstract}

Kata Kunci: Harga Pokok Produksi, harga jual, Break Even Point, keuntungan

\section{PENDAHULUAN}

Untuk mempertahankan pelanggan, sebuah organisasi selalu berusaha untuk memberikan pelayanan yang terbaik. Pelayanan terbaik tersebut diantaranya menyediakan opsi tambahan berupa makanan bayi usia enam bulan ke atas dan pudding sehingga orang tua tidak sulit mencari MPASI (Makanan Pendamping ASI) untuk bayi. Namun demikian, penjualan bubur organik dan pudding ini harus didasari dengan analisis estimasi biaya agar dapat meningkatkan keuntungan perusahaan apabila dasar - dasar perhitungannya dilakukan dengan benar.

Salah satu tempat untuk dilakukan analisis biaya adalah Mitra Indonesia Sehat (Procil) Karawang yang terletak di Cijalu, Karawang. Procil Karawang memproduksi bubur organik dan puding rasa untuk untuk bayi usia 6-8 bulan. Tujuan utama dari perusahaan ini adalah membantu para orang tua yang sibuk dan tidak sempat 
membuat MPASI agar bayi terhindar dari paparan pestisida, karena produk yang dibuat berbahan dasar organik.

Karena inovasi perusahaan ini yang membuat para orangtua terbantu, maka pelanggan terus saja bertambah setiap harinya. Untuk menghindari kekeliruan dalam perhitungan biaya dan menghindari adanya kerugian, peneliti bertujuan menganalisis biaya dan perhitungan harga pokok produksi.

\section{Akuntansi Biaya}

Akuntansi biaya adalah proses pencatatan keuangan yang di dalamnya terjadi penggolongan dan peringkasan atas suatu biaya produksi, penjualan produk ataupun jasa dengan menggunakan suatu cara-cara tertentu.

\subsection{Macam-Macam Biaya}

Berdasarkan fungsi pokok perusahaan:

\section{Biaya Produksi}

Biaya-biaya yang timbul akibat adanya fungsi produksi. Fungsi produksi adalah kegiatan mengolah bahan baku menjadi barang jadi dan siap untuk dijual. Biaya produksi terdiri dari biaya bahan baku, biaya tenaga kerja langsung, dan biaya overhead pabrik.

\section{Biaya Bahan Baku}

Biaya bahan baku terdiri dari dua bagian, biaya bahan baku langsung dan biaya bahan baku tidak langsung. Bahan baku langsung adalah bahan-bahan yang dapat secara mudah dan akurat ditelusuri ke produk jadi dan siap dijual, sedangkan bahan baku tidak langsung adalah bahan baku yang tidak dapat secara mudah dan akurat ditelusuri ke produk jadi dan siap jual.

\section{Biaya Tenaga Kerja Langsung}

Biaya tenaga kerja langsung dihitung dari banyaknya karyawan hadir dalam suatu peridoe dan akan dikurangi langsung dengan keterlambatan masuk kerja, utang karyawan, dan lain-lain.

\section{Biaya Overhead Pabrik}

Biaya overhead adalah biaya yang terdapat dalam produksi kecuali biaya bahan baku langsung dan biaya tenaga kerja langsung. Contoh dari biaya overhead, antara lain bahan penolong, bahan tambahan, tenaga kerja tidak langsung, pembelian suku cadang, depresiasi, listrik, dan bensin. 
Berdasarkan volume produksi:

\section{a. Biaya Variabel}

Biaya variabel menunjukkan jumlah per unit yang relatif konstan dengan berubahnya aktivitas dalam rentang yang relevan. Hal ini disebabkan biaya variabel dapat berubah secara proporsioanl terhadap perubahan aktivitas dalam rentang yang relevan. Contoh dari biaya variabel, antara lain biaya bahan baku, biaya bahan penolong, biaya bahan tambahan, dan pembelian suku cadang.

\section{b. Biaya Tetap}

Biaya tetap per unit semakin kecil seiring dengan meningkatnya aktivitas dalam rentangg yang relevan. Contoh biaya tetap, antara lain biaya tenaga kerja langsung, biaya tenaga kerja tidak langsung, biaya gedung, bensin, saluran air, peralatan, dan transportasi.

\subsection{Joint Cost}

Joint cost adalah biaya produksi yang menghasilkan sejumlah produk secara simultan.

Beberapa istilah yang digunakan antara lain:

a. Joint product dan by product

Istilah joint product digunakan untuk satu atau lebih produk yang dihasilkan dari satu proses produksi/operasi dengan nilai jual yang relative setara. $B y$ product sendiri adalah produk sampingan dari produk utama yang dihasilkan.

b. Titik split-off

Setelah proses produksi sampai produk bias dijual, maka produk dikatakan mencapai titik split-off. Jadi yang dimaksud titik split off adalah titik dimana produk-produk Bersama telah dipisahkan dan masing-masing siap untuk dijual atau diproses lebih lanjut.

\subsection{Metode Alokasi Biaya Bersama}

Biaya bersama dapat dipertanggungjawab kan dalam berbagai cara. Empat alternative untuk mengalokasikan biaya gabungan termasuk pengalokasian biaya berdasarkan:

1. Metode sales value pada titik split off.

2. Metode perhitungan fisik

3. Metode NRV (Net Realizable Value).

4. Metode constant gross margin percentage. 


\subsection{Titik Impas (BEP)}

Titik Impas (Break Even Point = BEP) adalah titik dimana total pendapatan sama dengan total biaya atau titik dimana laba sama dengan nol atau break even.

Menghitung titik impas dalam Unit:

BEP Unit $=\frac{T F C}{P-V C}$

Dimana:

TFC $=$ Total biaya tetap

$\mathrm{P} \quad=$ Harga jual per unit

$\mathrm{VC}=$ Biaya variabel per unit

Menghitung titik impas dalam Rupiah:

BEP Rupiah $=\frac{T F C}{1-\frac{V C}{P}}$

Dimana:

TFC = Total biaya tetap

$\mathrm{VC}=$ Biaya variabel per unit

$\mathrm{P} \quad=$ Harga jual per unit

\section{METODOLOGI PENELITIAN}

Jenis data yang digunakan berupa data kuantitatif, yaitu berupa angka besarnya biaya Harga Pokok Produksi, Harga Pokok Penjualan, harga jual per unit, Break Even Point unit, Break Even Point Rupiah, dan keuntungan perusahaan yang dilakukan secara langsung di tempat penelitian. Penelitian ini menggunakan data yang didapatkan melalui buku besar di Mitra Sehat Indonesia (Procil) Karawang. Pengamatan dilakukan selama 5 hari, untuk memperoleh data perhitungan biaya yang valid.

Pada penelitian ini peneliti menggunakan metode service hours dalam menghitung penggunaan asset secara penuh, Full Costing Method dalam menentukan HPP (Harga Pokok Produksi), Break Even Point Method dalam menentukan batas minimum penjualan untuk mendapatkan keuntungan di Mitra Sehat Indonesia (Procil) Karawang. 


\section{Pengumpulan dan Pengolahan Data}

Pengumpulan dan pengolahan data dilakukan setelah dilakukan pengamatan penelitian.

\subsection{Pengumpulan Data}

Pengumpulan data dilakukan melalui buku besar perusahaan dengan jangka waktu 1 bulan, sehingga mendapat hasil sebagai berikut.

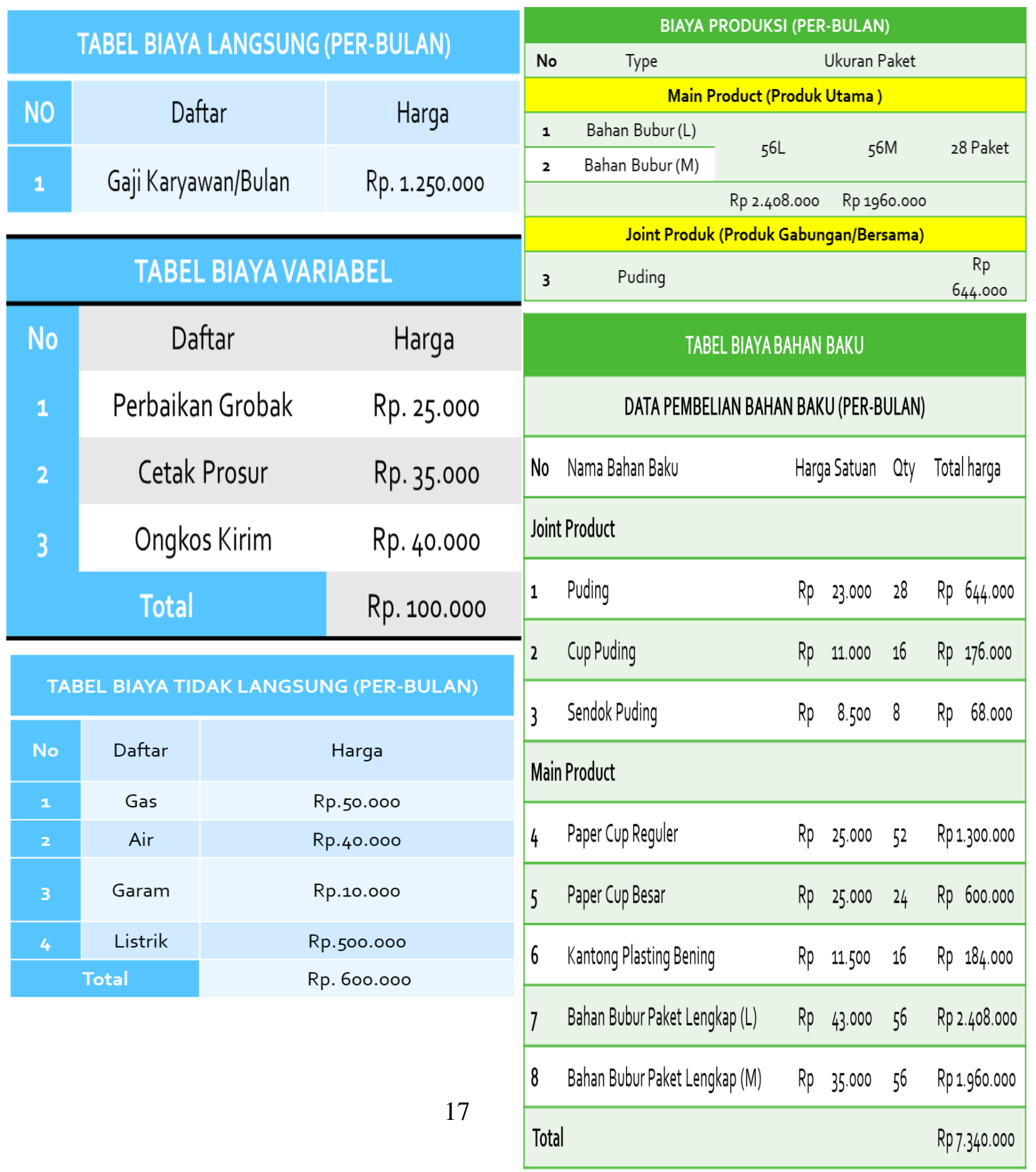




\begin{tabular}{|lcr|}
\hline No & \multicolumn{2}{c|}{ BIAYATETAP (PER-BULAN) } \\
\hline 1 & Sewa Tempat & 100.000 \\
\hline No & BIAYA ORDER (PER.MNNGGU) \\
\hline 1. & Pemesanan Bahan BakU & Tidak Terkena PPN/Tarif \\
\hline 2. & Logistik(Karawang) & RP.40.000/Mitra \\
\hline
\end{tabular}

\section{HASIL DAN PEMBAHASAN}

Pengolahan data yang dilakukan peneliti adalah dengan metode manual, di antaranya Service Hours Method, Full Costing Method dan Break Even Point Method.

\section{Harga Pokok Produksi}

Biaya - biaya yang termasuk dalam Harga Pokok Produksi (HPP), yaitu :

Biaya bahan baku langsung :

Pengeluaran yang dilakukan untuk pemakaian bahan baku produksi utama yang terkait langsung dengan produk yang akan dihasilkan. Bahan baku langsung dari Mitra Bubur Organik ini meliputi bahan-bahan organic dan bahan puding rasa. Berikut :

\section{Biaya bahan baku}

Bahan baku yang digunakan untuk membuat bubur organik \& Puding adalah Beras Organik (Paket Beras) \& Sayuran Organik (Paket Sayur) \& Ekstrak Puding Rasa.

56 Paket L Beras \& Sayur $\times$ Rp.43.000 (satuan) $=$ Rp. 2.408 .000 (dalam per bulan)

56 Paket M Beras \& Sayur $\times$ Rp.35.000 (satuan) $=$ Rp. 1.960 .000 (dalam per bulan) 28 Paket Puding $x$ Rp.23.000 (satuan) $=$ Rp.644.000 (dalam per bulan).

\section{Dalam 1 hari menghasilkan porsi :}

Pagi \& Sore

Paket $\mathrm{L}=88$ Porsi \& Paket $\mathrm{M}=68$ Porsi 
Puding Rasa $=22$ Cup

\section{Biaya Produksi Per Unit Bubur Organik}

Biaya bahan baku bubur organik per porsi adalah Rp.3.500 (Ketentuan Pusat Procil Anak Sehat), Jika kita hitung :

Biaya Paket L per porsi

\begin{tabular}{|c|c|}
\hline 1x Penjulan /hari Biaya Bahan PaketL & $R p, 143.000$ \\
\hline Biaya Listrik Rp, 500,000 bulan : 31 Hari & Rp.1.613)|hari \\
\hline Biaya Air Rp.400000:31 Hari & Rp.1.290 \\
\hline Biaya Garam Rp,10,000:31 Hari & Rp.322 \\
\hline Total Biaya Rp, 46.225 :88 porsi(12hari) & Rp.525/porsi PaketL \\
\hline
\end{tabular}

Biaya Paket M per Porsi

\begin{tabular}{|c|c|}
\hline 1X Penjulan /hari Biaya Bahan PaketM & $R P, 355.000$ \\
\hline Biaya Listrik Rp, 500,000 lbulan : 31 Hari & Rp.1.613|hari \\
\hline Biaya AirRpp,40,000:31 Hari & Rp.1.290/hari \\
\hline Biaya Garam Rp.10.000 :31 Hari & Rp.322/|hari \\
\hline Total Biaya Rp, 38.225; 68 porsi (Ihari) & Rp.552/porsi PaketM \\
\hline
\end{tabular}

Jadi penjualan Bubur Organik dalam per porsi $(\mathrm{L}+\mathrm{M})=$ Rp.1.087/porsi $=$ Rp.1.100/porsi (Jika dibulatkan).

\section{Biaya Produksi Per Unit Puding Rasa}

Biaya bahan baku pudding per cup adalah Rp.2.500 (Ketentuan Pusat Procil Anak Sehat), 
Jika kita hitung menggunakan perhitungan :

Puding Rasa Biaya per cup

\begin{tabular}{|c|c|}
\hline Harga 18ahan Pudinguntuk yxhari penvulalan & Rp.23.000 \\
\hline 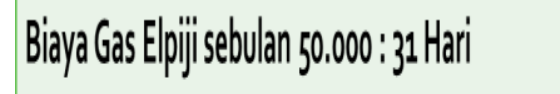 & Rp.1.6.3/|hari \\
\hline 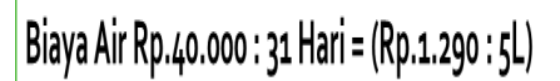 & Rp.258) Liter \\
\hline 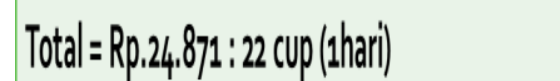 & Rp.1.130)(up \\
\hline
\end{tabular}

Jadi penjualan Puding Rasa dalam per cup Rp.1.130/Cup = Rp.1.200 (Jika dibulatkan).

\section{Laporan Keuangan Perusahaan}

\section{Penentuan Harga Pokok Produksi (HPP)}

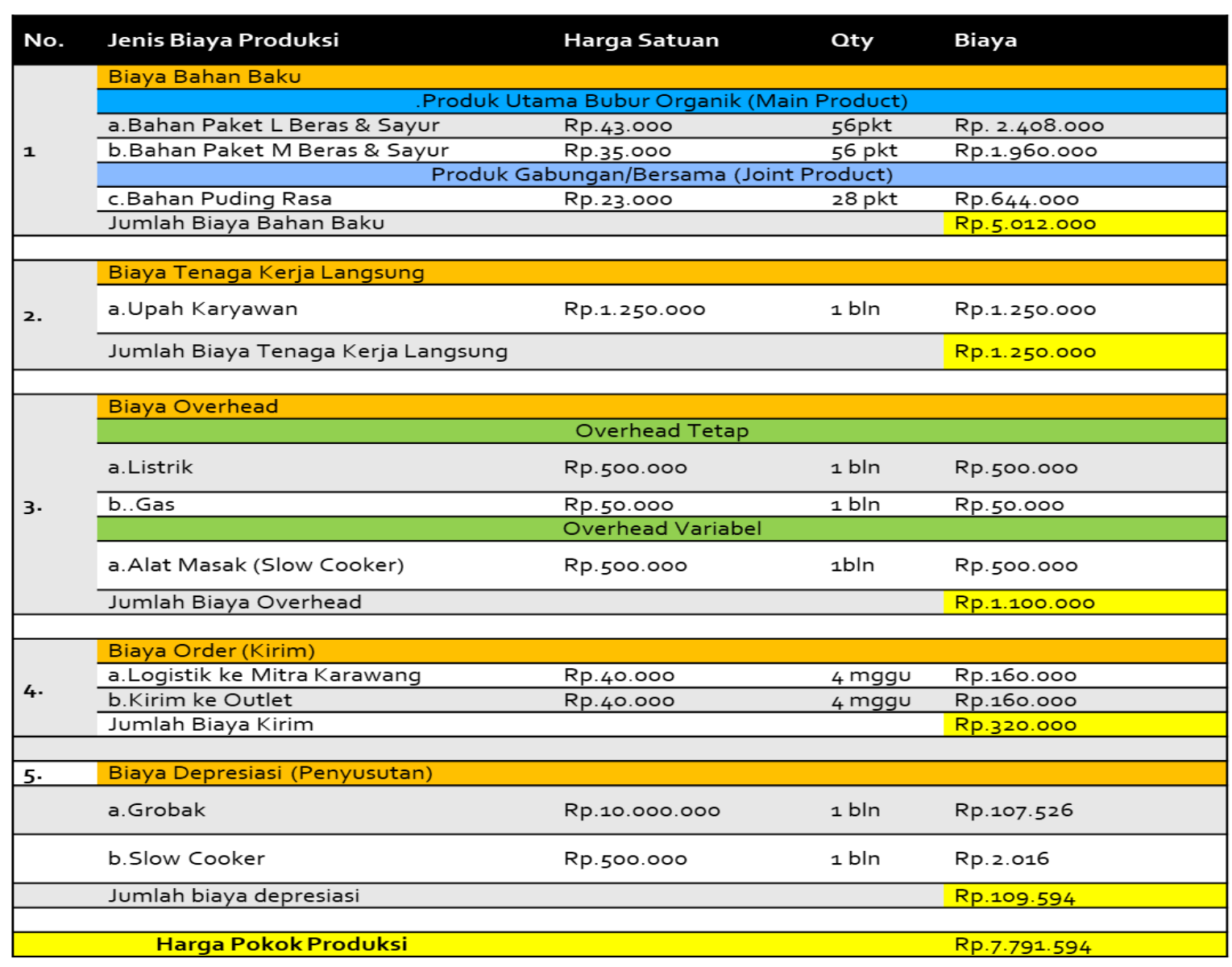


Jadi, Harga Pokok Produksi dalam periode 1 Bulan yang didapat dari Biaya Bahan Baku, Biaya Tenaga Kerja Langsung, Biaya Overhead baik (tetap \& variable), Biaya Kirim serta Biaya Depresiasi yaitu sebesar Rp.7.791.594.

\section{Penentuan Harga Jual (Mark Up Method)}

Mark Up Pricing dengan rumus:

Harga Beli + Mark Up = Harga Jual

Dimisalkan: (Mark Up Princing 25\% dari jumlah full costing)

\begin{tabular}{|ll|}
\hline Bahan Baku Langsung & Rp. 5.012 .000 \\
\hline Biaya Kirim & Rp.320.000 \\
\hline Tenaga Kerja Langsung & Rp.1.250.000 \\
\hline Biaya Overhead & Rp.1.100.000 \\
\hline Biaya Depresiasi & Rp. 109.594 \\
\hline Jumlah & Rp.7.791.594 \\
\hline Mark Up Princing & Rp.1.947.898 \\
\hline (25\%*7.791.594) & Rp.9.739.492 \\
\hline Harga Jual & \\
\hline
\end{tabular}

Jadi, Laba yang diinginkan dari penjualan selama 1 bulan dengan

1. Metode Mark Up Princing adalah sebesar 25\% Mark Up dikalikan Harga Pokok Produksi (HPP) Rp.7.791.594 yaitu sebesar Rp.1.947.898/bulan

2. Dengan Harga Jual yaitu Harga Beli Rp.7.791.594 ditambahkan Mark Up Rp.1.947.898 sebesar Rp.9.739.492

Penentuan Break Even Point (BEP)

BEP Main Product (Bubur Organik)

Penjualan Bubur Organik (dalam 1 bulan)

- Kapasitas Produksi dalam 1hari Pagi \& Sore sebanyak = 156 Porsi x 31 Hari = 4.836 Porsi 
- $\quad$ Harga Jual per porsi $=$ Rp.3500/porsi

Biaya Tetap (1 bulan)

\begin{tabular}{|ll|}
\hline Gaji & Rp.1.250.000 \\
\hline Sewa Lokasi & Rp. 100.000 \\
\hline Depresiasi & Rp. 109.594 \\
\hline Logistik & Rp. 320.000 \\
\hline Total & Rp.1.779.594 \\
\hline
\end{tabular}

Biaya Variabel (1 bulan)

\begin{tabular}{|c|c|}
\hline $\begin{array}{l}\text { Bahan Baku Paket L\&M } \\
\text { (Pagi \&Sore) }\end{array}$ & Rp.4.368.00c \\
\hline $\begin{array}{l}\text { Alat Penunjang (Slow } \\
\text { Cooker) }\end{array}$ & Rp. 500.000 \\
\hline Listrik & Rp. 500.000 \\
\hline Air & Rp. $\quad 40.000$ \\
\hline Garam & Rp. 10.000 \\
\hline Cup Bubur Besar & Rp. 600.000 \\
\hline Cup Bubur Regular & Rp.1.300.000 \\
\hline Kantong Plastik & Rp. 184.000 \\
\hline Perbaikan Grobak & Rp. 25.000 \\
\hline Total & Rp.6.927.000 \\
\hline
\end{tabular}

Total penjualan 4.836 Porsi (dalam penjualan 1 bulan) x Rp.3500 (Harga Bubur Per porsi) $=\mathbf{R p . 1 6 . 9 2 6 . 0 0 0}$

- $\quad$ Biaya Tetap Unit $=$ Rp.1.779.594 : 4.836 = 367,98 = Rp.368/porsi

- Biaya Variabel Unit $\quad=$ Rp.6.927.000 : 4.836= Rp.1.432/porsi

Untuk mencari BEP dalam Unit :

\section{BEP Unit}

$=$ Rp.1.779.594 FC : (3.500 P - Rp1.432 VC)

$=$ Rp.1.779.594 $: 2.068=860,538=\mathbf{8 6 1 , 8}$ porsi

Jadi, penjualan bubur organik di outlet Cijalu - Cikampek harus menjual 861,8 porsi. Untuk mencari BEP dalam Rupiah : 


\section{BEP Rupiah}

$$
\begin{aligned}
& =\frac{R p 1.779 .594}{1-\frac{R p .6 .927 .000}{R p .16 .926 .000}}=\frac{R p 1.779 .594}{0,5908} \\
& =\text { Rp.3.016.261 = Rp.3.016.300 }
\end{aligned}
$$

Jadi, Outlet Bubur Organik Cijalu - Cikampek harus mendapatkan omset sebesar Rp.3.016.300, agar terjadi BEP.

Untuk membuktikan kedua hasil tersebut :

$$
\begin{aligned}
& \mathrm{BEP}=\text { Unit BEP } \mathrm{x} \text { Harga Jual Unit } \\
& =861,8 \text { porsi } x \text { Rp. } 3500 \\
& \text { = Rp.3.016.300 (nilai seragam dengan BEP Rupiah) }
\end{aligned}
$$

Jadi, artinya untung karena penjualan sudah melampaui batas target untuk BEP sebanyak 861,8 porsi. Kita dapat hitung laba/profit dalam 1 bulan :

4.836 porsi (penjualan dalam periode 1 bulan) - 861,8 porsi (dalam target BEP) = 3.974 porsi x Rp.3500 (harga per porsi ) = Rp.13.909.000 keuntungannya.

\section{BEP Joint Product (Puding Rasa)}

- Kapasitas produksi dalam 1 hari sebanyak 22 cup x 31 hari = 682 cup

- Harga per cup sebesar Rp.2500/cup

Jadi penjualan puding rasa dalam 1 bulan sebanyak 628 cup (penjualan dalam 1 bulan) x Rp.2500 (harga per cup) adalah Rp.1.705.000

Biaya Tetap (1 bulan)

$\begin{array}{ll}\text { Paper Cup Puding } & \text { Rp.176.000 } \\ \text { Sendok Puding } & \text { Rp. } 68.000 \\ \text { Air } & \text { Rp. } 40.000 \\ \text { Gas } & \text { Rp. } 50.000 \\ \text { Total } & \text { Rp.334.000 }\end{array}$

Biaya Variabel (1 bulan)

Bahan Puding Rp. 644.000 
- $\quad$ Biaya Tetap Unit $=$ Rp. $334.000: 682=489,7=$ Rp. $.489 /$ cup

- Biaya Variabel Unit= Rp.644.000 : $682=$ Rp.944/cup

Untuk mencari BEP dalam Unit :

\section{BEP Unit}

$334.000 \mathrm{FC}:(2500 \mathrm{P}-944 \mathrm{VC})=334.000-1.556=\mathbf{2 1 4}$ cup

Jadi, penjualan puding rasa di outlet cijalu - cikampek harus menjual 214 cup,agar BEP.

Untuk mencari BEP dalam Rupiah :

\section{BEP Rupiah}

$=\frac{R p 334.000}{1-\frac{R p .644 .000}{R p .1 .705 .000}}=\frac{R p .334 .000}{\mathbf{0 , 6 2 2 2 8 7 3 9}}=\mathbf{R p . 5 3 6 . 7 2 9}$

Jadi, penjualan puding rasa pada outlet Cijalu - Cikampek harus mendapatkan omset sebesar, Rp.536.729 agar terjadi BEP.

Untuk membuktikan kedua hasil tersebut :

$$
\begin{aligned}
\mathrm{BEP} & =\text { Unit BEP } \times \text { Harga Jual Unit } \\
& =214 \text { cup } \times \mathrm{Rp} .2500
\end{aligned}
$$

\section{$=$ Rp.535.000 (nilai seragam dengan BEP Rupiah)}

Jadi, artinya untung karena penjualan sudah melampaui batas target untuk BEP sebanyak 214 cup. Kita dapat hitung laba/profit dalam 1 bulan:

628 cup (penjualan dalam periode 1 bulan) - 214 cup (dalam target BEP)

$=468$ cup $x$ Rp. 2500 (harga per porsi ) $=$ Rp.1.170.000 profit -nya .

\section{Total Keuntungan}

Profit/Laba Main Product (Bubur Organik) \& Joint Product (Puding rasa) selama 1 bulan

1. Main Product (Bubur Organik)

$$
=\text { Rp.13.909.000 }
$$




\section{Joint Product (Puding Rasa)}

$=$ Rp. 1.170 .000

Total profit $=$ Rp.15.079.000 / Bulan

\section{KESIMPULAN}

Berdasarkan hasil penelitian dan pembahasan yang diperoleh di Mitra Sehat Indonesia (Procil) Karawang, dapat diambil kesimpulan sebagai berikut:

1. Total biaya produksi selama 1 bulan untuk produksi pembuatan Bubur Organik dan Puding rasa pada Mitra Procil Outlet Karawang adalah sebesar Rp.7.791.594

2. Pada perhitungan laporan ini semua biaya adalah biaya proses pembuatan, sehingga jika ingin menghitung keuntungan produk dapat di tambahkan dengan keuntungan yang di inginkan, seperti di tabel Mark Up Princing sebesar 25\% dikali Harga Pokok Produksi (HPP) Rp.7.791.594.Maka Keuntungan / Laba yang diperoleh sebesar Rp.1.947.898.

3. Dalam 1 hari penjualan Produk Utama (Main Product) bubur organik paket L \& M pagi \& sore sebanyak 156 p orsi, jika dalam sebulan sebanyak 4.836 porsi yang terjual.

4. Dalam 1 hari penjualan Produk Bersama (Joint Product) Puding rasa sebanyak 22 cup, jika dalam sebulan sebanyak 682 cup yang terjual.

5. Harga Produksi per porsi dari Main Product / Produk Utama (Bubur Organik) adalah Rp.1.087/porsi atau dibulatkan untuk harga jual adalah Rp.1.100/porsi

6. Harga Produksi per cup dari Joint Product / Produk Gabungan (Puding Rasa) adalah Rp.1.130 atau dibulatkan untuk harga jual adalah Rp.1.200/cup

7. Penjualan Bubur Organik sudah melampaui batas target untuk BEP sebesar 861,8 porsi. Kita dapat hitung laba/profit dalam 1 bulan : 4.836 porsi (penjualan dalam periode 1 bulan) $-861,8$ porsi (dalam target BEP) $=3.974$ porsi x Rp.3500 (harga per porsi $)=$ Rp.13.909.000 profitnya.

8. Penjualan Puding rasa sudah melampaui batas target untuk BEP sebanyak 214 cup. Kita dapat hitung laba/profit dalam 1 bulan : 628 cup (penjualan dalam periode 1 bulan) -214 cup (dalam target BEP) $=468$ cup x Rp.2500 (harga per porsi $)=$ Rp.1.170.000 profitnya.

9. Profit/ Laba Main Product (Bubur Organik) + Joint Product (Puding rasa) Rp.13.909.000 + Rp. 1.170.000 = Rp.15.079.000

\section{DAFTAR PUSTAKA}

Putra, I. M. (2018). Akuntansi Biaya. Yogyakarta: Quadrant.

Lestari, W., \& Permana, D. B. (2017). Akuntansi Biaya Dalam Perspektif Manajerial. Depok: Rajawali Pers. 